\title{
Pediatric penetrating oropharyngeal trauma
}

\author{
Weiping Lei, MD $\cdot$ Jing Yu, MD $\cdot$ Yaqin Huang, MD $\cdot$ Li Zhao, MD $\cdot$ Jianliang Sun, MD
}

Received: 28 January 2019/Revised: 16 February 2019/Accepted: 18 February 2019/Published online: 14 March 2019

(C) The Author(s) 2019

A two-year-old male patient presented with penetrating oropharyngeal trauma. He had fallen while eating a corncob skewered by a chopstick. The chopstick had lodged in the roof of the patient's mouth and the corncob occluded the entrance (Figure A). A sagittal computed tomography $(\mathrm{CT})$ image showed the chopstick penetrating the hard palate, transiting the nasopharynx, and lodging into the skull base (Figure B). The coronal CT image showed that the chopstick had penetrated slightly left to the midline of the hard palate passing through the inner edge of the medial plate of the pterygoid canal (through which the pterygoid artery, vein, and nerve transit) (Figure C), though there was no sign of injury to the pterygoid canal. In the operating room, $30 \mathrm{mg}$ iv ketamine was titrated while spontaneous breathing was maintained. To allow for preoxygenation with a facemask, we dissected the corncob and cut the chopstick with a surgical rongeur. The patient was then intubated after intravenous induction of anesthesia (Figure D). The surgical and postoperative courses were otherwise uneventful.

This case presented the anesthetic dilemma of mananging a full stomach and near complete obstruction of the oral airway. It is important to consider that the patient would likely have aspirated had he vomited, even though he was alert and had intact protective airway reflexes when he presented, as the nasal airway was too small to remove stomach contents. Also, as the penetrating oropharyngeal trauma may have caused major vascular injuries as a lateral soft palate or peritonsillar injury could have posed a potential risk to the internal carotid artery injury, ${ }^{1}$ a CT scan was urgently conducted. Had a vascular injury been suspected, CT angiography could have further identified its extent. ${ }^{2}$ Based on this patient's CT scan, if he had started to vomit before commencing surgery, we would have immediately removed the chopstick and corncob to protect the airway, despite the potential risk of hemorrhage.

W. Lei, MD · Y. Huang, MD · L. Zhao, MD · J. Sun, MD (ه)

Department of Anesthesia, the Affiliated Hangzhou First

People's Hospital, Zhejiang University School of Medicine,

Hangzhou, China

e-mail: jxmzsj1@163.com

J. Yu, MD

Department of Anesthesia, Zhejiang Xiaoshan Hospital,

Hangzhou, China 
Figure Anesthesia

management of a pediatric patient with penetrating oropharyngeal trauma. A) A cobcorn skewered by a chopstick occluded the mouth. B) A sagittal computed tomography (CT) scan showed that the chopstick had lodged in the skull base, with the coronal CT image (C) showing that the chopstick had passed through the inner edge of the medial plate of the pterygoid canal. D) The patient was successfully intubated after the corncob had been removed and the chopstick cut away to allow laryngoscopy.
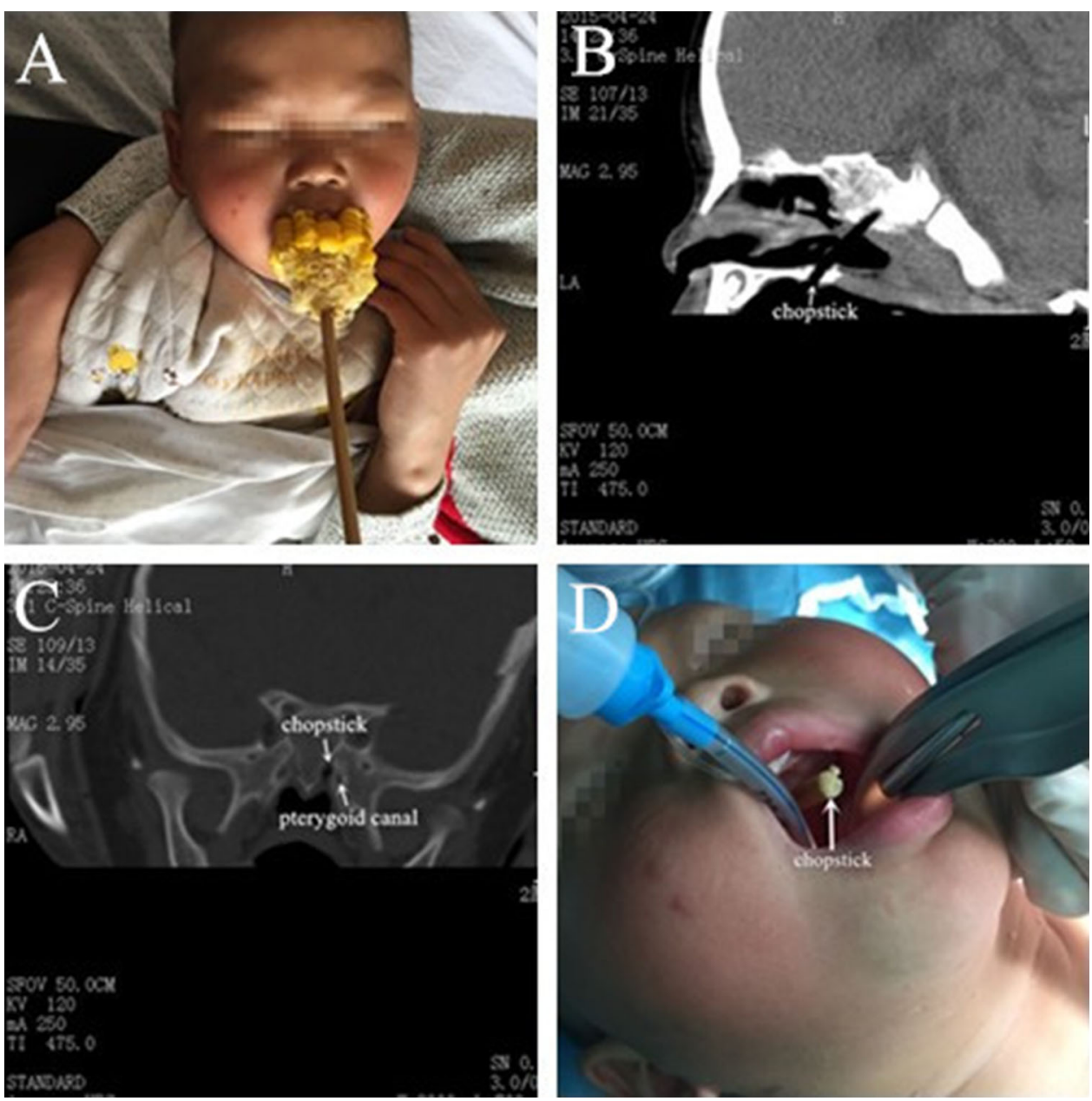

Acknowledgement We are grateful to Guoming Xie MD, PhD, MSc who provided feedback on this paper.

Financial disclosure This manuscript was supported by the Natural Science Foundation of Zhejiang Province Y17C09009).

Editorial responsibility This submission was handled by Dr. Hilary P. Grocott, Editor-in-Chief, Canadian Journal of Anesthesia.

Open Access This article is distributed under the terms of the Creative Commons Attribution-NonCommercial 4.0 International License (http://creativecommons.org/licenses/by-nc/4.0/), which permits any noncommercial use, distribution, and reproduction in any medium, provided you give appropriate credit to the original author(s) and the source, provide a link to the Creative Commons license, and indicate if changes were made.

\section{References}

1. Soose RJ, Simons JP, Mandell DL. Evaluation and management of pediatric oropharyngeal trauma. Arch Otolaryngol Head Neck Surg 2006; 132: 446-51.

2. Brietzke SE, Jones DT. Pediatric oropharyngeal trauma: what is the role of CT scan? Int J Pediatr Otorhinolaryngol 2005; 69: 669-79.

Publisher's Note Springer Nature remains neutral with regard to jurisdictional claims in published maps and institutional affiliations. 